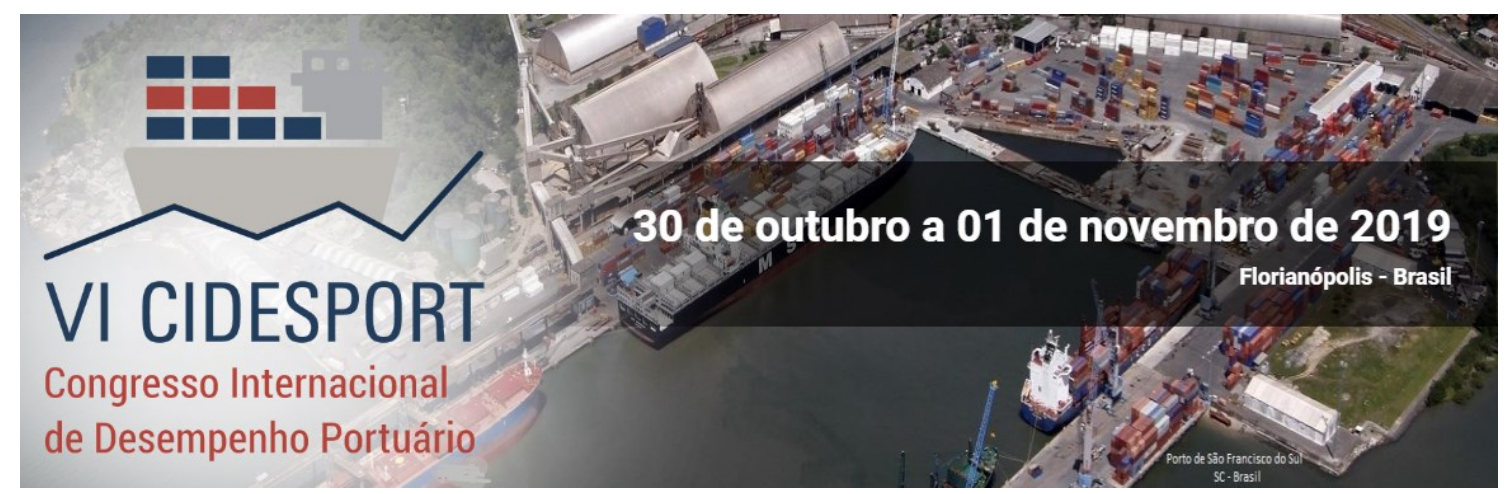

\title{
USO DE INDICADORES DE GESTÃO COMO CRITÉRIO NA ALOCAÇÃO DE RECURSOS DE DRAGAGEM EM PORTOS PÚBLICOS BRASILEIROS
}

\author{
Daniele Moraes Electo de Paiva \\ Universidade Federal do Rio de Janeiro \\ Gardenio Diogo Pimentel da Silva \\ Universidade Federal do Rio de Janeiro \\ Gabriel Kvassay \\ Universidade Federal do Rio de Janeiro \\ Guilherme de Moura Haguenauer \\ Universidade Federal do Rio de Janeiro

\section{Marcos de Freitas Universidade Federal do Rio de Janeiro}

Resumo: São muitos os desafios do setor portuário brasileiro, em especial nos portos públicos. A quase ausência de investimentos em infraestrutura por décadas ficou evidente com a abertura comercial, e agravada pela evolução dos tamanhos das frotas marítimas mundiais. Para atender à sua função de interface comercial, os portos brasileiros precisam de constantes dragagens de manutenção, visando atender ao tamanho dessas frotas, e assim viabilizar custos menores, aumentando sua competitividade. A movimentação portuária, supostamente, deve se beneficiar dessas obras de dragagem, e é frequentemente utilizada como indicador de desempenho. No entanto, alguns portos não têm correspondido à expectativa de crescimento na sua movimentação. Este estudo buscou demonstrar uma correlação entre as obras de dragagem e o aumento da movimentação de cargas portuárias, tomando como base uma análise de série histórica da Agencia Nacional de Transportes AquaviáriosANTAQ. Após esta análise, conclui-se que é preciso apontar os fatores que têm atravancado os negócios nessas unidades portuárias e, para tanto, apontar uma série de indicadores que podem ser aplicados para esse fim. $\mathrm{O}$ uso de indicadores pode cooperar com critérios de decisão de alocação de recursos para dragagem, por parte do Governo Federal, responsável pela sua contratação. Os indicadores citados neste estudo têm como foco a gestão portuária e a capacidade de desenvolvimento de negócios dos portos, de forma que, uma vez contemplados com serviços de dragagem, o aumento na movimentação portuária seja, de fato, consolidado, trazendo desta forma desenvolvimento econômico aos setores envolvidos. É necessário que gestores portuários sejam consultados para que se identifique fatores que atravancam a gestão, para que propostas sejam ouvidas e o alinhamento de objetivos seja consolidado.

Palavras-chaves: Dragagem. Indicadores. Gestão. Negócios.

* A revisão gramatical, ortográfica, ABNT ou APA foi realizada pelos autores. 


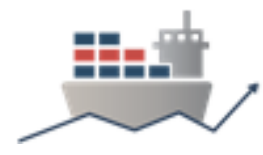

\section{INTRODUÇÃO}

Os portos públicos e privados representam a interface da cadeia logística que permite a comercialização de produtos desde os lugares mais recônditos, por meio de modais variados de transporte (com seus desafios e vantagens) até o consumidor final da cadeia mundial.

No Brasil, os portos públicos em especial, enfrentam há décadas desafios relacionados à infraestrutura e gestão, com reflexo no valor final das mercadorias que circulam por essas interfaces de logística, afetando a economia do país de forma direta ou indireta.

A manutenção do funcionamento dessas interfaces, os portos, requer uma vasta gama de ações, dentre elas, as dragagens dos canais de acesso, que de forma simplificada, pode ser justificada em função de dois fatores principais:

- Taxa de assoreamento do canal de acesso que, em alguns casos, a localização desfavorável em enseadas e áreas estuarinas imprimem taxas ainda mais expressivas de assoreamento;

- Aumento das dimensões das frotas marítimas mundiais.

Sabendo-se que a contratação de serviços de dragagem em portos públicos é uma responsabilidade do Governo Federal, que esses serviços são executados por empresas estrangeiras e que os custos associados são elevados, é necessário que critérios sejam aplicados ao processo de decisão e destinação de recursos financeiros.

Obras de dragagem têm finalidades diversas, mas no Brasil, atualmente se aplicam ao aprofundamento e manutenção de canais de acesso aos portos marítimos, sob a justificativa da necessidade de se possibilitar a chegada de navios de maior porte, aumento no volume de atracações, melhorando a competitividade dos portos e consequentemente, o aumento na movimentação de cargas.

No entanto, após a conclusão da primeira fase do Programa Nacional de Dragagem (PND I), com investimentos de $R$ \$ 1,6 bilhão, e a remoção do volume aproximado de 73 milhões de metros cúbicos em 16 portos, nota-se que os resultados em alguns dos portos contemplados não corresponderam à expectativa de melhoria nos números relacionados à movimentação de cargas.

O presente estudo busca contribuir com a sugestão de critérios para melhor identificação de portos com potencial de aumento de competitividade e crescimento a partir de indicadores de gestão e da execução dos serviços de dragagem nos canais de acesso desses portos. Este estudo apresenta campos de interesse na gestão portuária que podem ser melhor explorados para a produção de indicadores que possam ser úteis quando da decisão e alocação de verbas federais.

\section{REFERENCIAL TEÓRICO}

\subsection{Necessidade "natural" de dragagem}

A Lei 12.815, de 5 de junho de 2013, "Lei dos Portos", define dragagem como obra ou serviço de engenharia que consiste na limpeza, desobstrução, remoção, derrocamento ou escavação de material do fundo de rios, lagos, mares, baías e canais.

A dragagem de acessos aquaviários marítimos ou fluviais requer grande investimento de recursos técnicos e financeiros, que devem ser justificáveis pela necessidade dos usos desses acessos, ou finalidade dada ao material dragado. No 


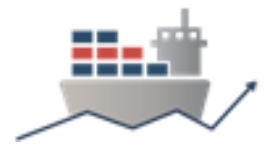

caso dos portos marítimos, a garantia da navegação implica na garantia da movimentação de cargas e passageiros para fins comerciais.

Segundo o Departamento de Meio Ambiente e Ciência (Department of Environment and Science) de Queensland - Austrália, em seu Guia de Dragagem (2018), há três tipos de atividades relacionadas à dragagem, quais sejam:

- Extração de material para aplicação em construções;

- Dragagem de aprofundamento com propósitos de navegação (usualmente na criação de novos canais de navegação, berços de atracação, marinas, bacias de manobra); e

- Dragagem de manutenção para se garantir que os canais, berços, bacias de manobra e outras áreas do porto mantenham as dimensões necessárias para seus propósitos, para manutenção de maré natural para navegação ou mitigação de inundações.

Sendo assim, as aplicações da dragagem vão desde o aprofundamento e alargamento de canais, lagos e rios, ao aterramento de áreas alagadas, por meio do processo de remoção e/ou deposição de sedimentos (material dragado) do fundo de um curso d'água qualquer.

No caso dos canais de acesso aos portos, as correntes marítimas, e em muitas vezes, o aporte de matéria orgânica a esses locais acabam por provocar o assoreamento, bem como de áreas de manobra, e acessos aos berços.

Além da necessidade constante de dragagem que possibilite o acesso marítimo aos portos acesso aos portos, devido ao assoreamento diminuição do calado, outro fator deve relacionado à profundidade requerida para navegação nesses acessos, qual seja a evolução no tamanho da frota marítima comercial mundial.

Trinta anos atrás, o maior navio de contêineres tinha capacidade de 4.500 TEU (Navio Panamax), enquanto que hoje, o maior navio de contêineres tem capacidade de aproximadamente 22.000 TEU. (HARALAMBIDES, 2019).

Ainda, um navio conteinero com capacidade para pelo menos 180 mil toneladas necessita 16 metros de calado (distância vertical entre a quilha e a linha de flutuação). Já os construídos até a década de 1990, com capacidade de no máximo 60 mil toneladas, são atendidos por um calado de 12 metros (MENEGAZZO E PETTERINI 2017).

Esse crescimento no tamanho das frotas deve-se à economia de escala, que busca maximizar os ganhos uma vez que os custos relativos a custos e competitividade caem à medida que o tamanho do navio aumenta (HARALAMBIDES, 2019).

Ainda no contexto da economia de escala, o mesmo autor utiliza a imagem a seguir, Figura 2-1: Navios exemplo de economia de escala na indústria navalFigura 2-1, dos navios conteineros Antoine de Saint Exupéry (maior) e American Lancer (menor).

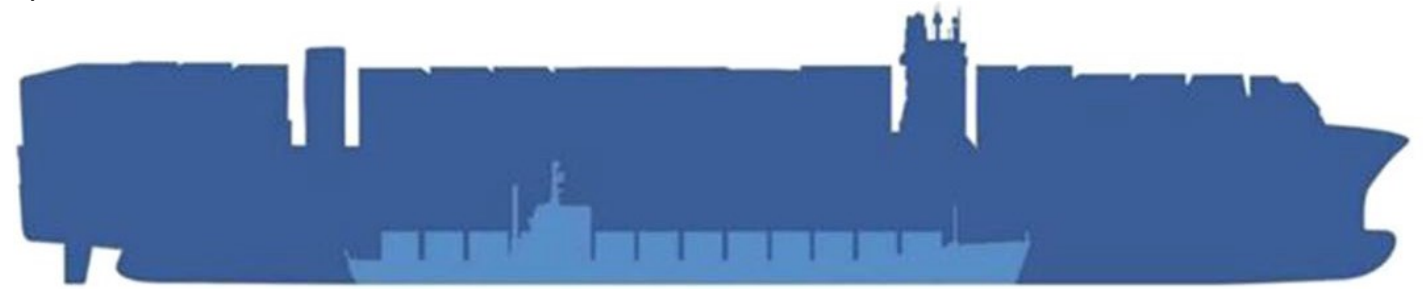

Figura 2-1: Navios exemplo de economia de escala na indústria naval Fonte: HARALAMBIDES, 2019

A seguir dados relativos às dimensões dos dois navios 


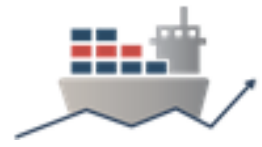

Quadro 2-1: Comparativo de dimensões de navios

\begin{tabular}{|c|c|c|c|c|}
\hline Navio & Ano & Comprimento $(\mathrm{m})$ & Largura $(\mathrm{m})$ & $\begin{array}{c}\text { Capacidade } \\
\text { (TEUs) }\end{array}$ \\
\hline American Lancer & 1968 & 213 & 26 & 1.200 \\
\hline Antoine de Saint Exupéry & 2018 & 400 & 59 & 20.776 \\
\hline
\end{tabular}

Nota-se que o navio Antoine é aproximadamente duas vezes maior em comprimento e largura que o navio Lancer, mas tem capacidade 17 vezes maior, sendo um bom exemplo de economia de escala.

Além da profundidade do canal de acesso, segundo Lima (2012) para que haja segurança na navegação, outros fatores são considerados. São eles:

- Profundidades na bacia de evolução e berços de atracação;

- Calado máximo das embarcações para entrada e saída do porto;

- Comprimento e boca máximos das embarcações;

- Variação das profundidades em função do assoreamento;

- Manobras recomendadas; e

- Informações sobre hidrografia e meteorologia.

Percebe-se a gama variada dos serviços que devem ser executados para a garantia da navegação de entrada e saída dos navios nos portos. A dragagem, se bem planejada e executada, os serviços de monitoramento de maré e de assoreamento, além de controle do tráfego marítimo são ferramentas que constantemente são aplicadas para mitigação e amenização da complexidade da navegação marítima.

\subsection{Responsabilidade por investimentos na dragagem}

No Brasil, a instabilidade política tem influenciado negativamente a evolução serviços básicos de infraestrutura como o de transporte. No setor portuário, ficou evidente, nos anos 1990, o nível de carência de investimentos uma vez que essa década foi marcada pela abertura do comércio internacional, cujas relações dependem da organização logística, sendo fundamental um sistema portuário eficiente e capaz de acompanhar as evoluções na frota marítima.

O setor já se encontrava deficitário, e ainda no início da década, em 1991, ocorreu a extinção da Empresa de Portos do Brasil S.A. (Portobras), que era a autarquia responsável por melhorias na gestão portuária.

Em 1993, também é extinta a Companhia Brasileira de Dragagem (CDB), e a responsabilidade das obras de dragagem foi transferida para a administração das instalações portuárias. Os altos custos envolvidos, e a falta de recursos financeiros e equipamentos implicaram a ausência de investimentos na manutenção da profundidade dos canais de acesso por parte das autoridades portuárias (LOPES, 2014).

O fim da década de 1990, no setor portuário brasileiro, foi marcado pela falta de dragagens regulares, e em 2007, o Plano Nacional de Dragagem foi instituído para operacionalizar as obras nas instalações públicas, passando a ser uma competência da Secretaria de Portos (SEP).

Segundo dados da Secretaria Nacional de Portos, o PND I, lançado em 2007, teve como resultado a remoção de aproximadamente 73 milhões de metros cúbicos de sedimentos em 16 portos. Em 2012, O PND II foi lançado, com previsão de que 


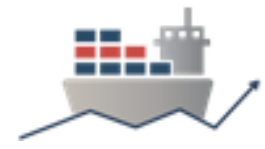

sejam dragados 44,5 milhões de metros cúbicos de sedimentos do canal de acesso de quatro portos (BRASIL, 2015)

No entanto, a dependência do poder público na tomada de decisão e investimentos no setor portuário tem gerado consequências tais, que refletem no aumento de custo de seguros e custos de demurrage, que é o valor pago sobre estadia decorrente da extrapolação do tempo de uso de equipamentos e serviços (IPEA 2010 apud MENEGAZZO E PETTERINI 2017).

Os valores de demurrage, ou taxa de demora, são pagos aos transportadores, que em sua maioria são estrangeiros, e ocorre quando o prazo estabelecido de tempo livre para devolução do contêiner é extrapolado pelo importador ou exportador, ou seja, o afretador (WINTER, 2017).

Sendo assim, é previsível que em portos com infraestrutura deficiente, as operações de carga e descarga gerem custos maiores, colocando-os em desvantagem em relação a outros, quando em concorrência por afretamentos.

Além dos altos custos relacionados às operações de cargas, os portos perdem em competitividade conforme a disponibilidade de rotas de escoamento de cargas, e planejamento organizacional logístico, constituindo as redes de fluxo de cargas em terra.

O planejamento e execução, de fato, dos sistemas de transportes e logística, tendem a cooperar com uma reorganização territorial mais equilibrada. Porém, a desigualdade territorial da distribuição de investimentos públicos e privados fizeram com que houvesse maior desenvolvimento no aumento da fluidez e competitividade de alguns territórios, em detrimento de outros (Silveira, 2018).

Dado o cenário pouco favorável ao crescimento econômico dessas unidades, considerando-se os problemas de infraestrutura e logística, e a dependência de investimentos, questiona-se como definir, em uma escala de critérios, quais os portos públicos devem ser priorizados.

\subsection{Indicadores de desempenho}

Estabelecer uma política de priorização por meio da comparação entre portos é tarefa complicada, uma vez que, segundo UNCTAD (2016), essas unidades de distribuição apresentam vasta gama de serviços, múltiplos atores e tomada de decisão e produção do desenvolvimento, gestão e operação portuários, em alto nível de complexidade.

Indicadores de desempenho portuário podem contribuir nesse processo, e conforme Wu; Yan; Liu, 2009 apud Dutra et al., (2014) os portos se beneficiam em competitividade a partir de um processo de avaliação de desempenho bem conduzido, além de servir como base de informações aos formuladores de políticas de desenvolvimento.

Indicadores devem atender às necessidades de diferentes atores como demandas de políticos responsáveis pela formulação de regras destinadas ao setor portuário; investidores, como forma de projetar seus ganhos; e gestores portuários que precisam de uma base comparativa segura para benchmarking e planejamento estratégico. Porém, a dificuldade na avaliação desses indicadores provém do número de parâmetros envolvidos, ausência de dados disponíveis que sejam reais e confiáveis, concordância dos atores envolvidos, forte influência de fatores locais nos dados obtidos e interpretações divergentes em função de interesses diversos para resultados idênticos UNCTAD (2016). 


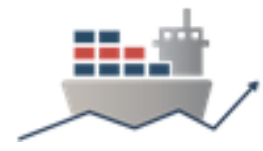

Alguns indicadores de desempenho são frequentemente utilizados $\mathrm{e}$ disponibilizados pela Agência Nacional de Transportes Aquaviários (ANTAQ), e estão relacionados ao aparato de equipamentos e procedimentos operacionais, como por exemplo, produtividade (prancha média), tempo médio de operação, de atracação, de estadia e outros. Em se tratando de portos públicos, é preciso ressaltar sua relação direta com baixos investimentos públicos no setor, e o sucateamento de algumas unidades portuárias reflete diretamente nos resultados desses indicadores.

Problemas na infraestrutura portuária brasileira estão relacionados a sua baixa capacidade de atendimento em função de fatores como: (i) apoio inadequado de logística e armazenagem; (ii) de tempo de desembaraço das cargas e, (iii) ausência de dragagem de manutenção dos canais de navegação, controle inadequado do trânsito marítimo, baixa disponibilidade e agilidade dos práticos e rebocadores, e outros (MENEGAZZO, PETTERINI, 2017). Esses fatores influenciam diretamente no desempenho portuário, por meio da aplicação de indicadores, usualmente aplicados à área operacional.

Uma pesquisa para o levantamento dos indicadores mais utilizados em pesquisas no setor portuário mostrou a aplicação com maior frequência daqueles indicadores com foco na avaliação da eficiência dos portos, sob a ótica operacional em detrimento de indicadores estratégicos (DUTRA, 2014).

A movimentação portuária é um indicador de desempenho, e pode ser útil a partir de uma série histórica e informações adicionais que possibilite análise de fatores que influenciaram a movimentação. A dragagem pode ser um desses fatores, e no Brasil, essa relação dragagem x movimentação portuária $(\mathrm{t})$, a manutenção ou aumento da competitividade e por consequência melhoria de relações econômicas, tem sido o parâmetro norteador na tomada de decisão para alocação de recursos de dragagem.

Menegazzo e Petterini (2017) em seu estudo "Maiores Navios no Mundo, mais um Desafio no Brasil: uma análise do Programa Nacional de Dragagem", utilizam o modelo de resultados potenciais preconizado por Neyman-Rubin, e utilizam a média mensal da movimentação de carga por navio atracado como indicador de impacto. Foram levadas em conta intervenções sofridas pelos portos como forma de dragagem, exposição a diferentes condições climáticas e regime de marés, problemas relacionados a licenças ambientais, licitações e embargo de obras, e outros. O estudo teve como principal conclusão é a necessidade de melhoria no PND, buscando-se resultados mais efetivos, uma vez que é crucial para se conseguir redução nos custos de frete e logística.

Um estudo realizado pela Organização Européia de Portos Marítimos em 2010, chamado "Port Performance Indicators: Selection and Measurement" (PPRISM) indicadores selecionados a partir de uma vasta seleção acadêmica, e posterior avaliação por membros da Organização Européia de Portos Marítimos, a European Sea Ports Organization (ESPO). O estudo aponta indicadores a serem aplicados às seguintes áreas de desempenho:

- Estrutura e tendências do mercado;

- Impacto Socioeconômico;

- Desempenho ambiental;

- Desempenho da cadeia logística e operacional;

- Governaça.

Este estudo serviu de base para o desenvolvimento de um vasto levantamento de variáveis que influenciam no desempenho portuário pela UNCTD, chamado Linking Performance Indicators to Strategic Objectives em 2016. 
O ScoreCard desenvolvido pela UNCTAD (2016), para avaliação do desempenho portuário, sugere como áreas estratégicas a serem usadas como indicadoras de desempenho, a área financeira (investimentos, lucros, ativos, cash, solvência), clientes (Parcela de mercado, análise de portfólio, eficácia dos serviços), operações (movimentação de navios e cargas, provisão de serviços, meio ambiente) e recursos humanos (treinamento, eficiência, organização, segurança, salários).

Espera-se, com a aplicação do ScoreCard, segundo a UNCT (2016), examinar ações nas quatro áreas estratégicas que são, ou deveriam ser desenvolvidas pelas autoridades portuárias

As áreas citadas, e indicadores relacionados às mesmas devem ser estudados de para aplicação local, ou seja, obedecendo-se características regionais. Por exemplo, o desempenho ambiental de portos públicos brasileiros pode utilizar parâmetros tais como consumo de energia, consumo de água, existência de programas de monitoramento, etc. assim como em países europeus. No entanto, tratando-se de governança, e estrutura institucional do setor portuário nacional apresenta restrições à aplicação dos indicadores sugeridos pelo PPRISM. Da mesma forma, alguns indicadores de impacto socioeconômico podem ser aplicados para a realidade brasileira.

Para este estudo, o foco se concentra na necessidade de inclusão de indicadores relacionados gestão portuária, para o auxílio à tomada da de decisão para a priorização de recursos para dragagem, conforme será mostrado no item 6.

\subsection{Critério de escolha dos portos analisados}

Considerando-se a localização geográfica dos portos contemplados e seus modais de transporte disponíveis e o conceito de hinterlândia, um estudo do IPEA (2015) sobre competitividade entre portos brasileiros mostra que para se investigar o grau de concentração entre portos, pode-se utilizar índices de concentração calculando-se as participações de mercado dos portos.

Medidas de concentração de mercado são utilizadas para quantificar a proximidade da estrutura de um setor de mercado quanto às situações de monopólio ou de concorrência perfeita. $O$ grau de concorrência e o nível de eficiência tendem a aumentar, na medida em que o nível, ou grau de concentração, diminui. De outra forma, maior grau de concentração de mercado implica maior probabilidade de ocorrência de comportamento de monopólio (VARUM et al., 2016).

Os resultados de um estudo do IPEA, de 2015, mostram que os indicadores de concorrência aplicados a fluxos de cargas de importação e exportação no Brasil em Estados da costa tendem a utilizar serviços portuários dentro do próprio Estado, tendo havido pouca variação nesse índice ao longo de quinze anos. Relativo às relações comerciais estabelecidas com localidades do interior do país, os indicadores de concentração são menores, mostrando que agentes exportadores e importadores contratam serviços de estados variados. Portanto, o fator geográfico é um dos fatores mais considerados pelos agentes quando da escolha de qual porto utilizar.

E enfim, o estudo conclui que aumento da competitividade entre os portos está diretamente relacionada à investimento na infraestrutura interna de transportes rodoviário, ferroviário e hidroviário.

\section{METODOLOGIA}

O processo metodológico utilizado foi a pesquisa do tipo exploratória, por meio de pesquisas bibliográficas. 


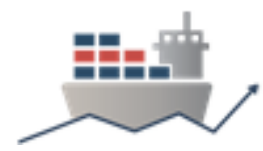

Tendo por finalidade a movimentação de navios que podem acessar os portos, é de se esperar que executados serviços de dragagem em um determinado porto, haja resultados positivos no que tange a movimentação de cargas. Porém, quanto é esperado de crescimento em um determinado período de tempo? Quais fatores devem ser considerados para que de fato esse crescimento ocorra, uma vez executada a dragagem?

A partir do número de atracações em portos e dados disponíveis na plataforma digital da ANTAQ (Agência Nacional de Transportes Aquaviários), foram construídos gráficos para análise de dados de movimentação de carga e número de atracações de dez portos públicos marítimos.

As informações referem-se a portos que, conforme divulgado pelo Ministério da Infraestrutura, disponíveis em https://www.infraestrutura.gov.br/images/arquivospnd/programa-nacional-de-dragagem-pnd1-pac-1.pdf, receberam dragagem de manutenção com investimentos do Programa Nacional de Dragagem (PND I).

Tendo-se como base o estudo desenvolvido pelo IPEA, dos portos contemplados pelas dragagens do PND I, e buscando-se eliminar possíveis discrepâncias relacionadas à competitividade, optou-se por usar como exemplos deste estudo, portos de proximidade geográfica, em função do grau de concentração do mercado, em três blocos geográfico distintos, quais sejam, região nordeste, sudeste e sul.

As características de tipo de cargas movimentadas pelos portos (graneis líquidos, sólidos ou contêineres) não foram consideradas, uma vez que o presente estudo não faz comparação entre portos. Uma avaliação comparativa de efeitos da dragagem do PND deveria levar em conta efeitos de outros fatores na movimentação de cargas, alheios às intervenções do PND (MENEGAZZO \& PETTERINI, 2017).

Sendo assim, no Nordeste são apresentados os portos do Recife, Cabedelo e Suape, Salvador e Aratu; no Sudeste, os portos do Rio de Janeiro e Santos; e na região Sul, os portos de Itajaí, Rio Grande, e São Francisco do Sul.

O número de atracações é relevante, sabendo-se que os serviços podem ser otimizados a partir da dragagem, já que um canal de maior calado permite que navios de maior porte acessem as instalações portuárias e, portanto, este parâmetro é observado em conjunto com o volume de cargas movimentado. Sendo assim:

- Aumento na movimentação em toneladas e aumento no número de atracações indicam que mais navios estão acessando o porto, mas os ganhos em escala não são necessariamente garantidos. Pode-se dizer que a infraestrutura do porto trabalha de forma eficiente o suficiente para atender um número maior de navios.

- Queda na movimentação em toneladas e queda no número de atracações após a execução dos serviços de dragagem indicam a possibilidade de existência de problemas de ordens diversas. Na infraestrutura, na gestão do porto, logística, contratos, etc.

- Aumento na movimentação em toneladas e queda no número de atracações indicam que navios maiores podem acessar o porto, em função do maior calado, após dragagem. A infraestrutura eficiente em conjunto com a maior capacidade de navios aumenta os ganhos em escala.

Percebe-se que o melhor cenário de resultados seria aumento na movimentação de cargas (em toneladas), e queda no número de atracações. 
VI CIDESPORT/2019

Congresso Internacional

de Desempenho Portuário

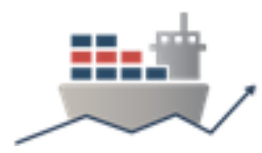

\section{RESULTADOS}

Os gráficos a seguir foram elaborados intencionando-se a exposição da evolução desses parâmetros após dragagens do PND I, executadas em alguns portos. A seguir, são apresentadas as séries históricas de movimentação e números de atracações nos portos citados, para o período de 2010 a 2018.

\section{- Região Nordeste}
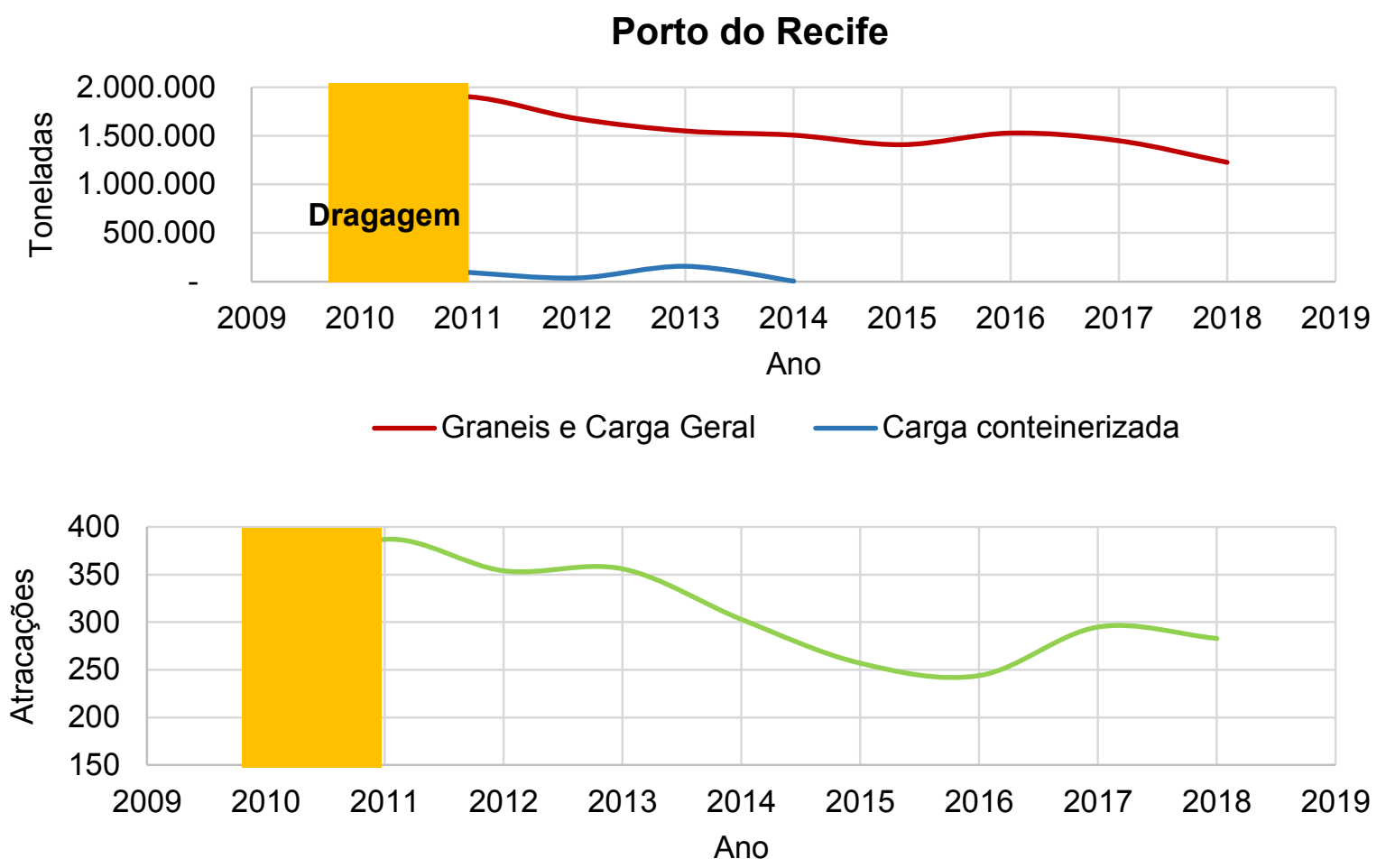

Figura 4-1: Toneladas movimentadas e número de atracações de 2010 a 2018 no Porto do Recife.

Fonte: Elaboração própria a partir de dados da ANTAQ, 2019.

Nota-se que apesar de ocorrida a dragagem, houve queda no montante movimentado pelo porto, e acompanhando a tendência de queda, o número de atrações também diminuiu. 
VI CIDESPORT/2019

Congresso Internacional de Desempenho Portuário
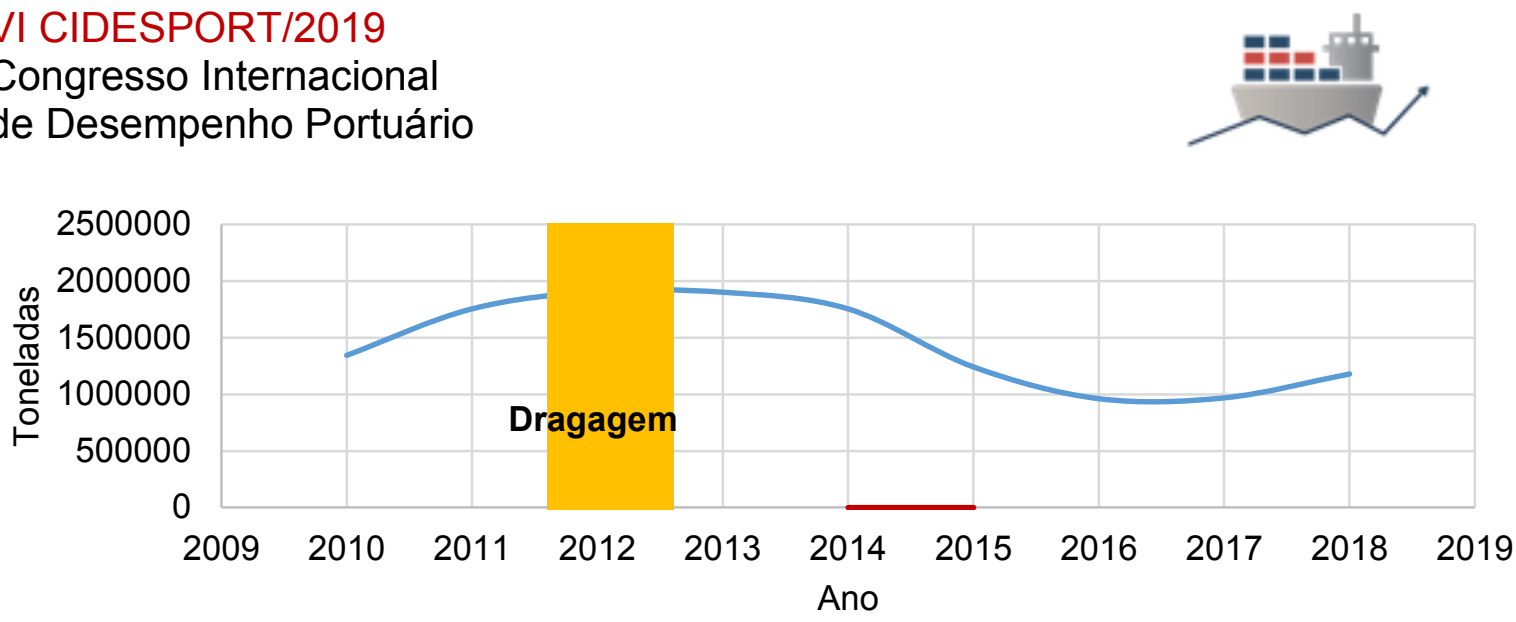

- Graneis e Carga Geral —Carga Conteinerizada

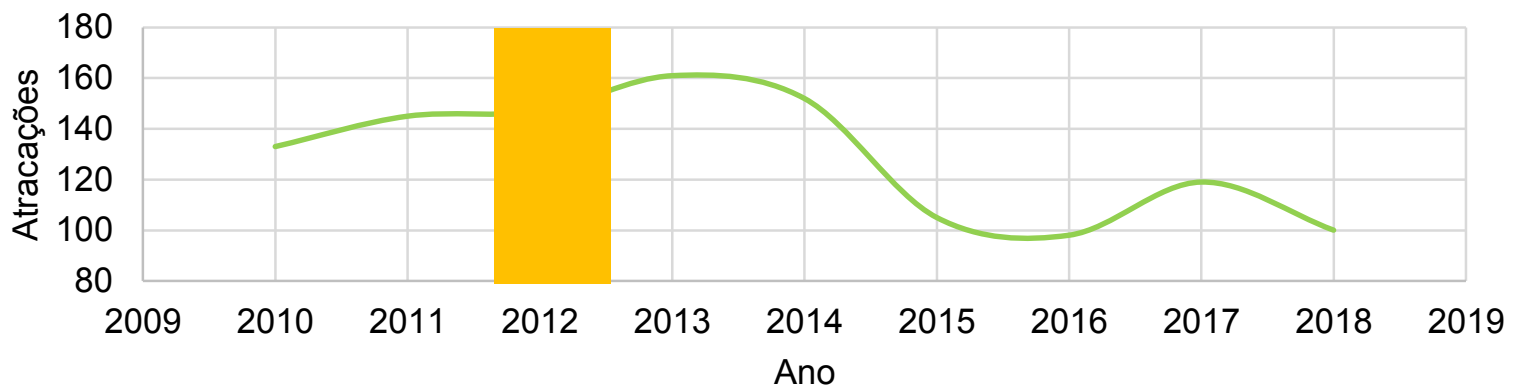

Figura 4-2: Toneladas movimentadas e número de atracações de 2010 a 2018 no Porto de Cabedelo.

Fonte: Elaboração própria a partir de dados da ANTAQ, 2019.

Em Cabedelo, assim como no Porto do Recife, houve queda na movimentação com leve início de recuperação em meados de 2017, bem como queda no número de atrações.

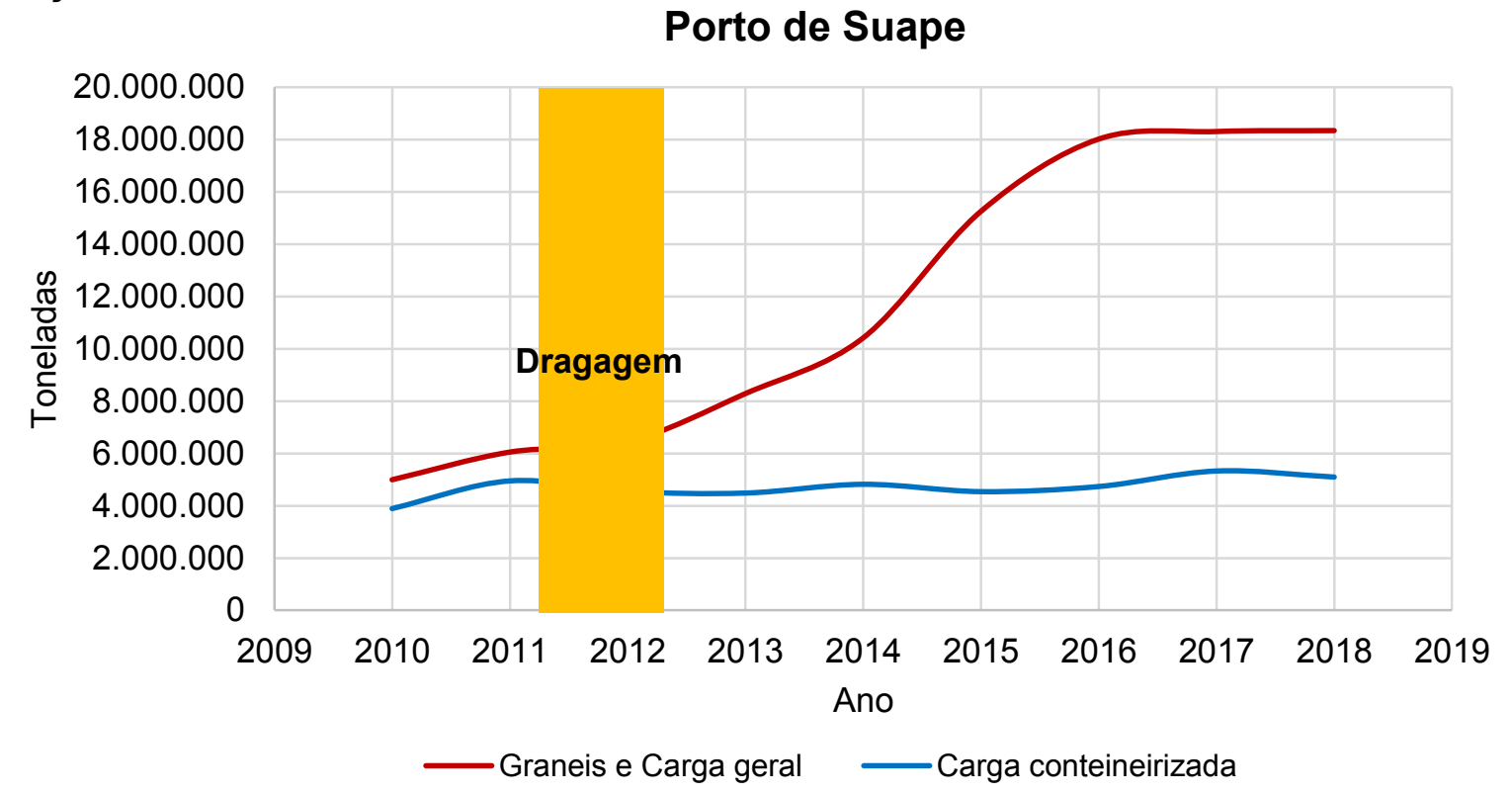


VI CIDESPORT/2019

Congresso Internacional de Desempenho Portuário
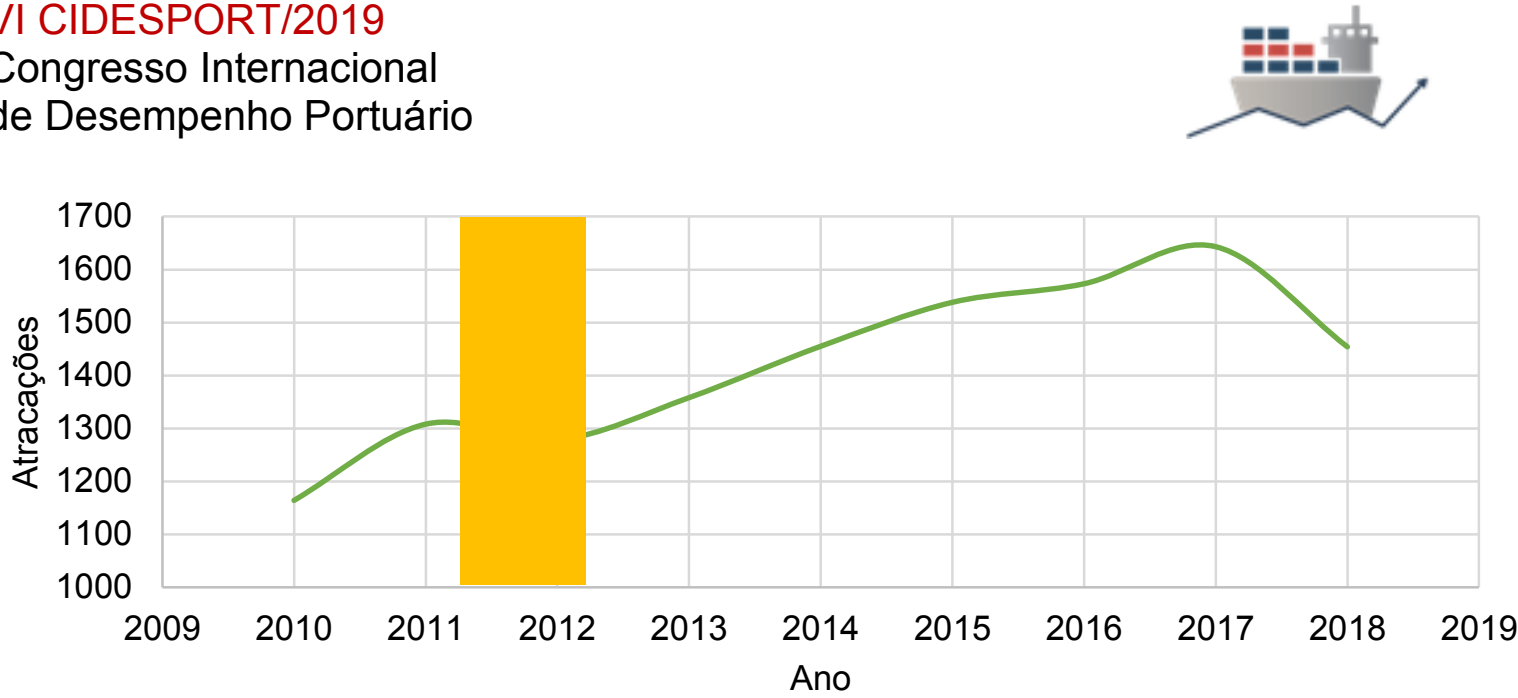

Figura 4-3: Toneladas movimentadas e número de atracações de 2010 a 2018 no Porto de Suape.

Fonte: Elaboração própria a partir de dados da ANTAQ, 2019.

No Porto de Suape, o que se observa após as obras de dragagem, é o aumento tanto na movimentação de cargas, como no número de atracações.

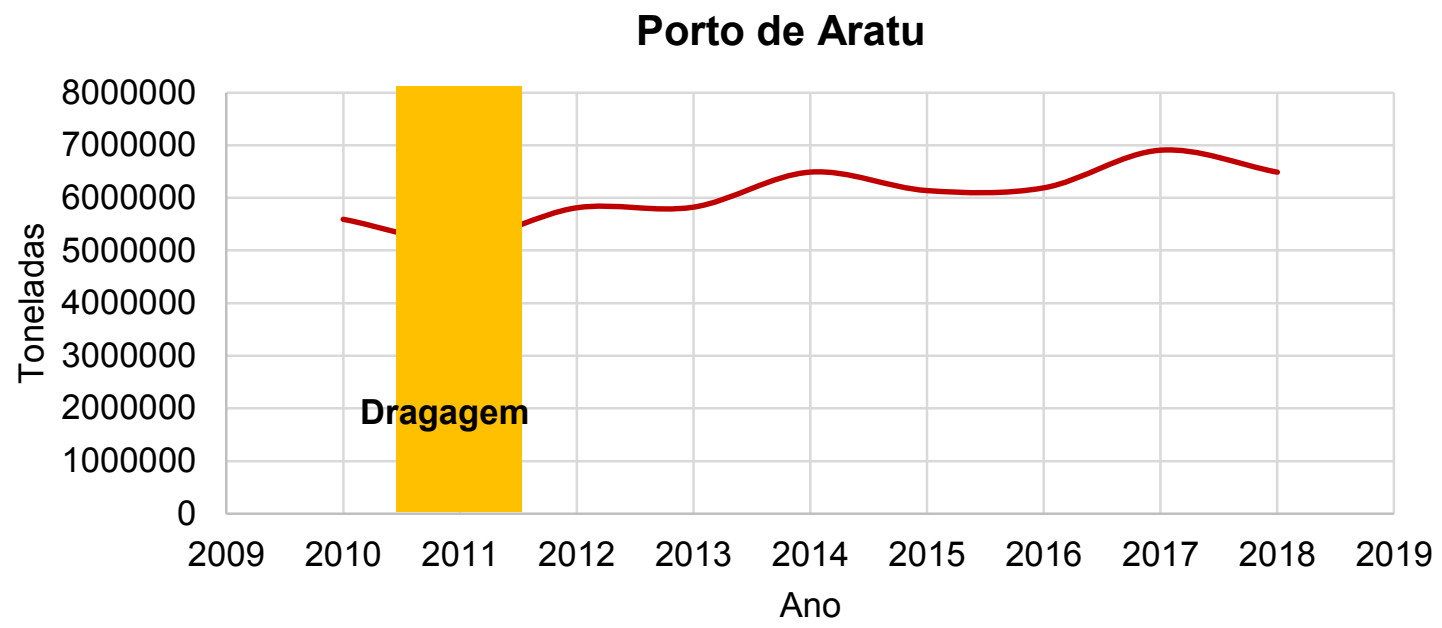

- Graneis e Carga geral

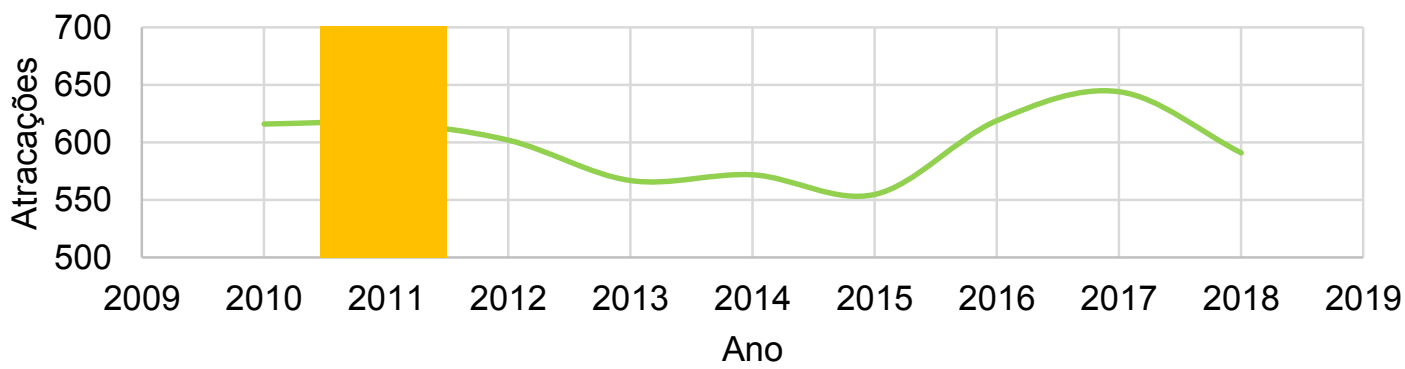

Figura 4-4: Toneladas movimentadas e número de atracações de 2010 a 2018 no Porto de Aratu.

Fonte: Elaboração própria a partir de dados da ANTAQ, 2019.

Percebe-se leve aumento no quantitativo da movimentação, sendo que no ano de 2017, quando os melhores índices foram alcançados, com 6.907.829 t movimentadas, o maior número de atracações também ocorreu no Porto de Aratu, 644 atracações. 


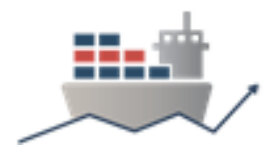

\section{Porto de Salvador}
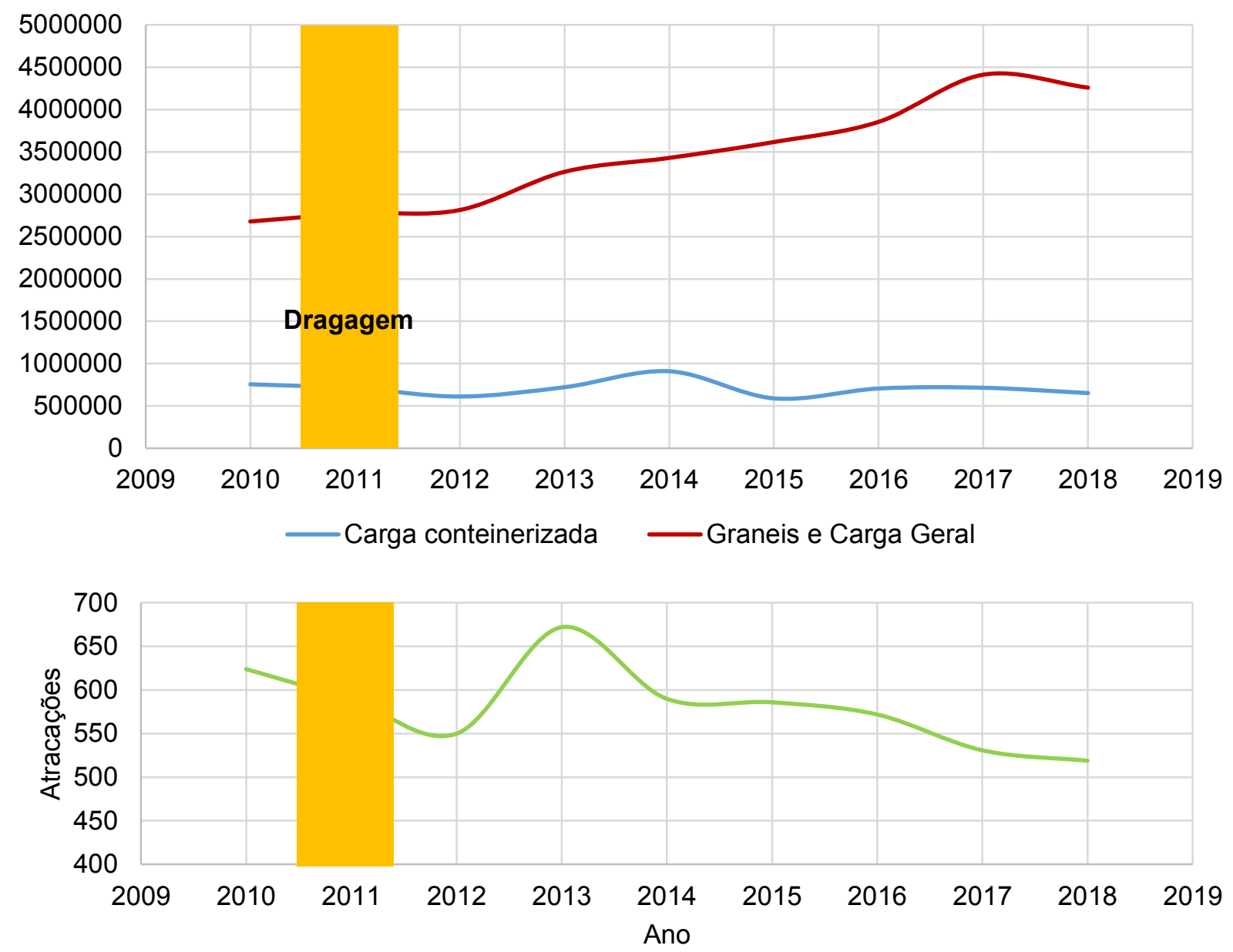

Figura 4-5: Toneladas movimentadas e número de atracações de 2010 a 2018 no Porto de Salvador.

Fonte: Elaboração própria a partir de dados da ANTAQ, 2019.

Os resultados obtidos pelo Porto de Salvador obedecem à melhor situação, em que há aumento na movimentação ao mesmo tempo em que o número de atracações cai, indicando ganho em escala. 
VI CIDESPORT/2019

Congresso Internacional

de Desempenho Portuário

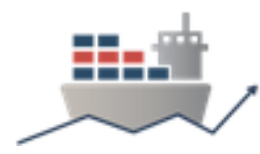

- Região Sudeste

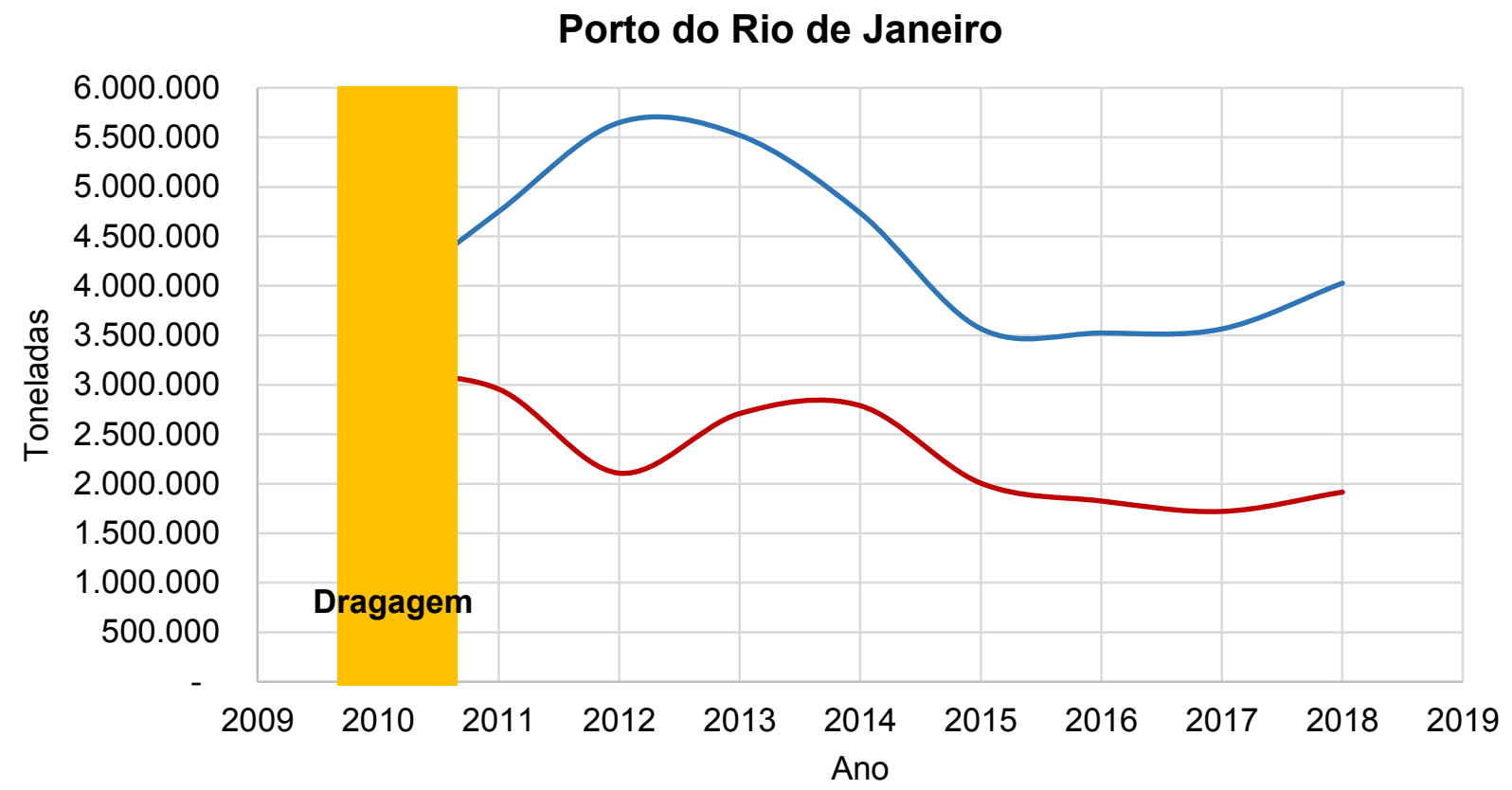

- Graneis e Carga geral —Carga Conteinerizada

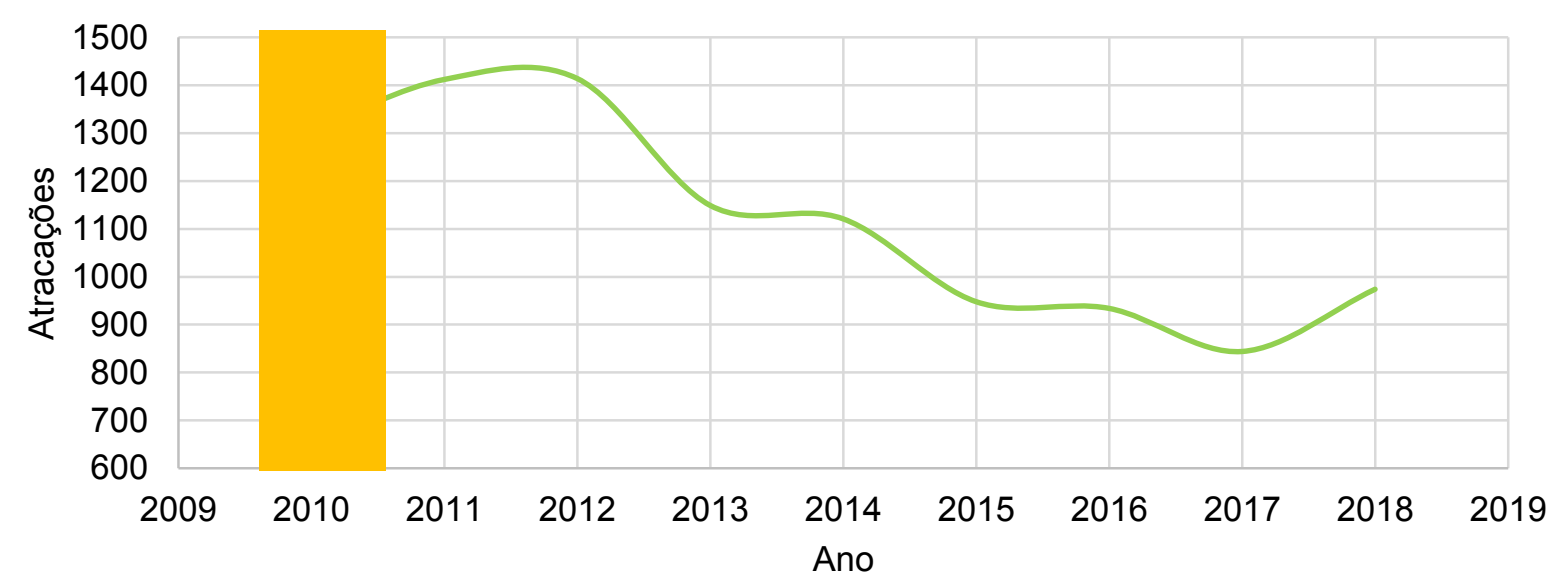

Figura 4-6: Toneladas movimentadas e número de atracações de 2010 a 2018 no Porto do Rio de Janeiro.

Fonte: Elaboração própria a partir de dados da ANTAQ, 2019.

O Porto do Rio de Janeiro apresentou resultado positivo até início de 2012, quando tanto o quantitativo movimentado, quanto o número de atracações passaram a se deslocar no sentido não favorável à economia do porto. Ou seja, queda na movimentação e aumento no número de atracações. 
VI CIDESPORT/2019

Congresso Internacional de Desempenho Portuário

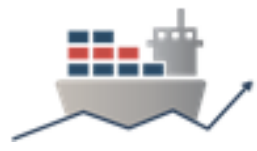

Porto de Santos
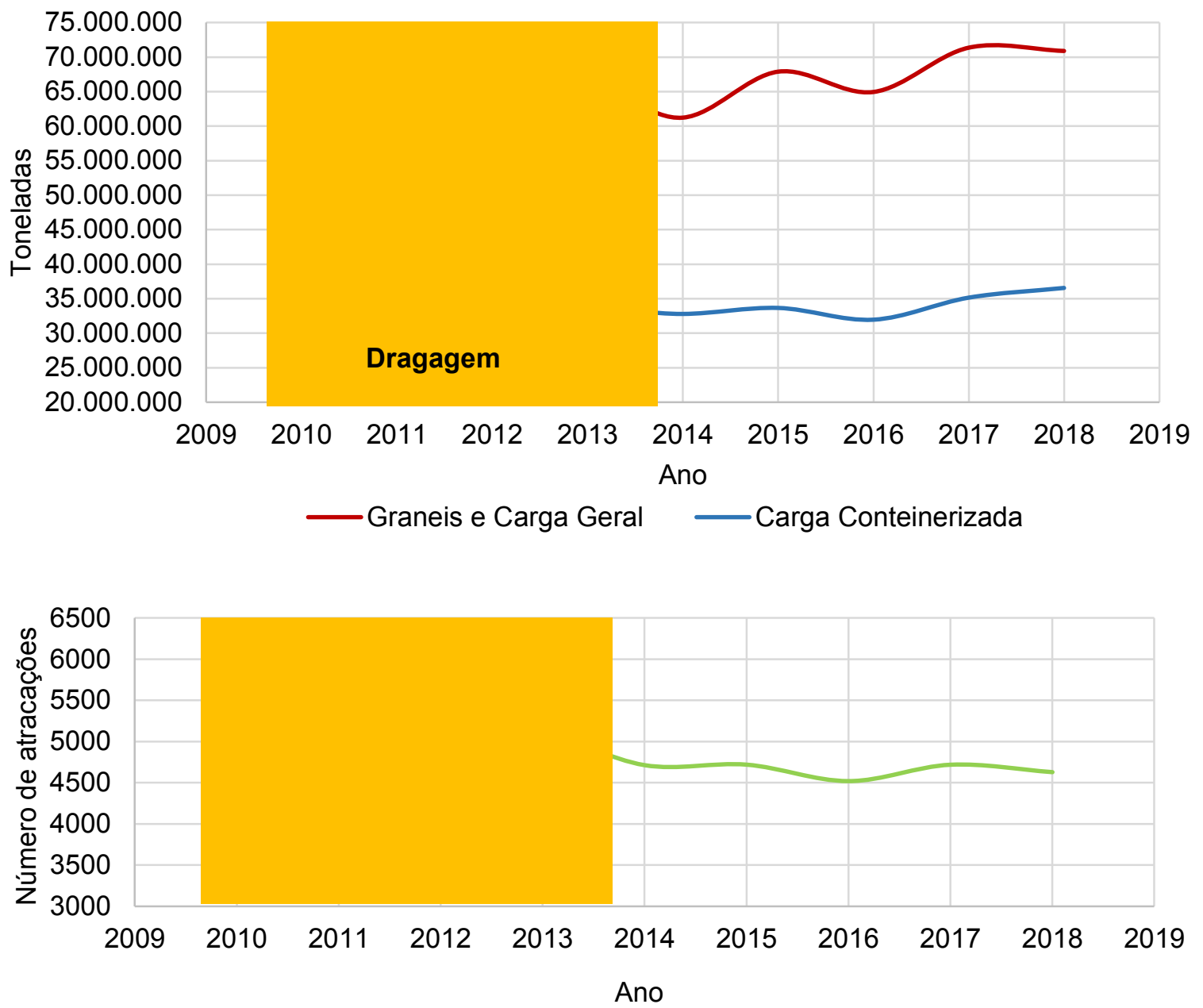

Figura 4-7: Toneladas movimentadas e número de atracações de 2010 a 2018 no Porto de Santos.

Fonte: Elaboração própria a partir de dados da ANTAQ, 2019.

Após a dragagem, nota-se que no Porto de Santos, houve resultados positivos tanto do ponto de vista da movimentação de cargas, como no número de atracações. 
VI CIDESPORT/2019

Congresso Internacional

de Desempenho Portuário

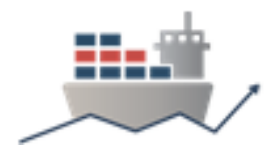

- Região Sul
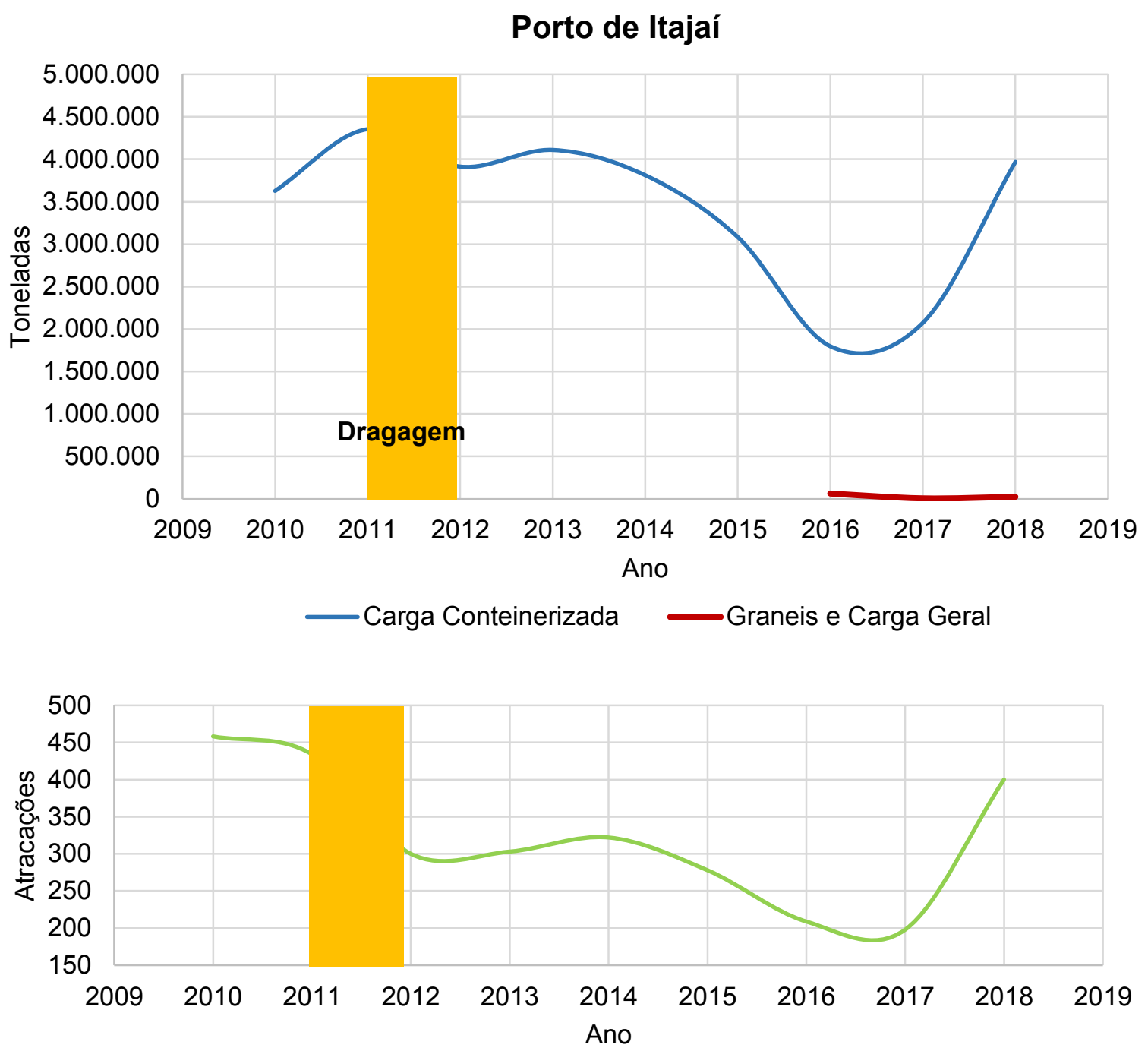

Figura 4-8: Toneladas movimentadas e número de atracações de 2010 a 2018 no Porto de Itajaí.

Fonte: Elaboração própria a partir de dados da ANTAQ, 2019.

Após execução da dragagem, observou-se que ambos parâmetros, movimentação de cargas e atracações, entraram em queda, no Porto de Itajaí. A diferença no quantitativo de toneladas movimentadas entre 2011 (melhor ano), para 2016 (pior ano da série) chega a aproximadamente 59\%. 
VI CIDESPORT/2019

Congresso Internacional de Desempenho Portuário

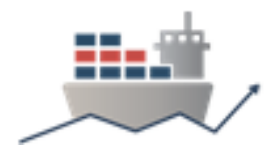

\section{Porto do Rio Grande}

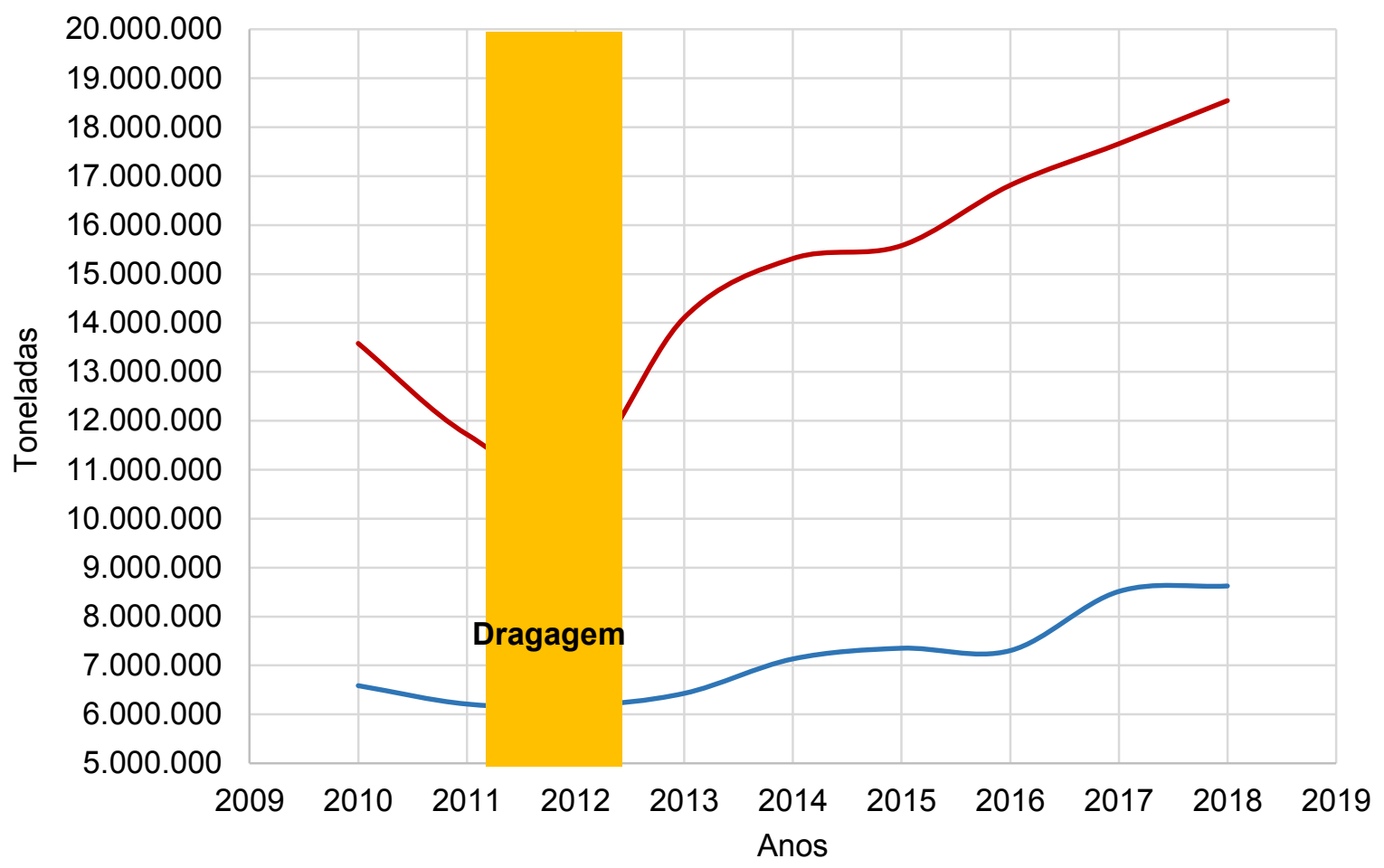

— Graneis e Carga Geral —Carga Conteinerizada

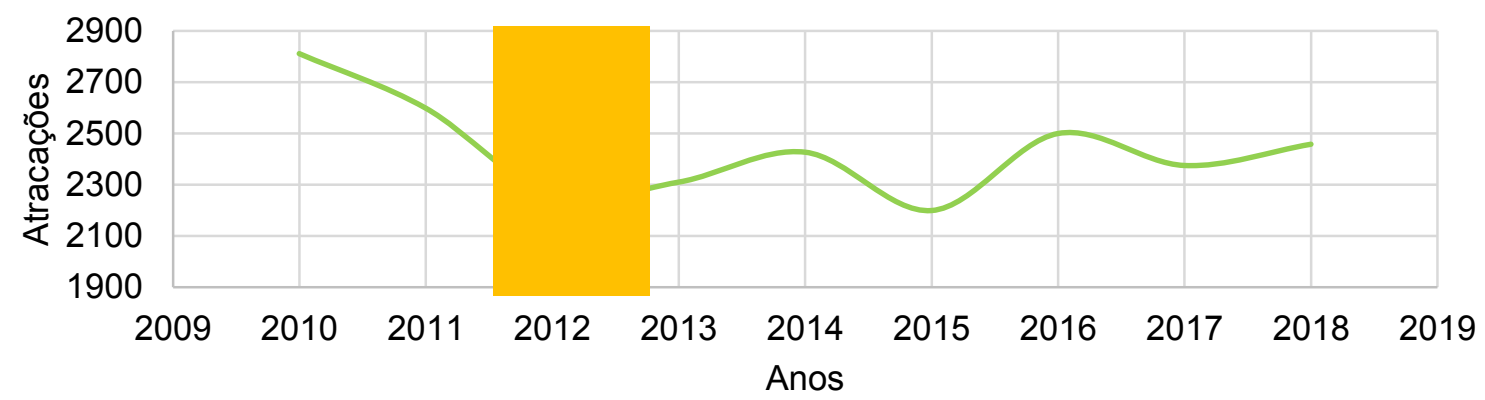

Figura 4-9: Toneladas movimentadas e número de atracações de 2010 a 2018 no Porto do Rio Grande.

Fonte: Elaboração própria a partir de dados da ANTAQ, 2019.Rio Grande

Observando-se a movimentação de cargas do Porto do Rio Grande, nota-se o crescimento constante e significativo após a execução da dragagem. De meados de 2012 a 2018, houve aumento aproximado de $40 \%$ na movimentação em toneladas. Relativo ao número de atracações, houve leves flutuações ao longo dos anos, com números variando entre 2100 e 2500 atracações anuais. 


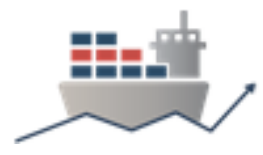

\section{São Francisco do Sul}

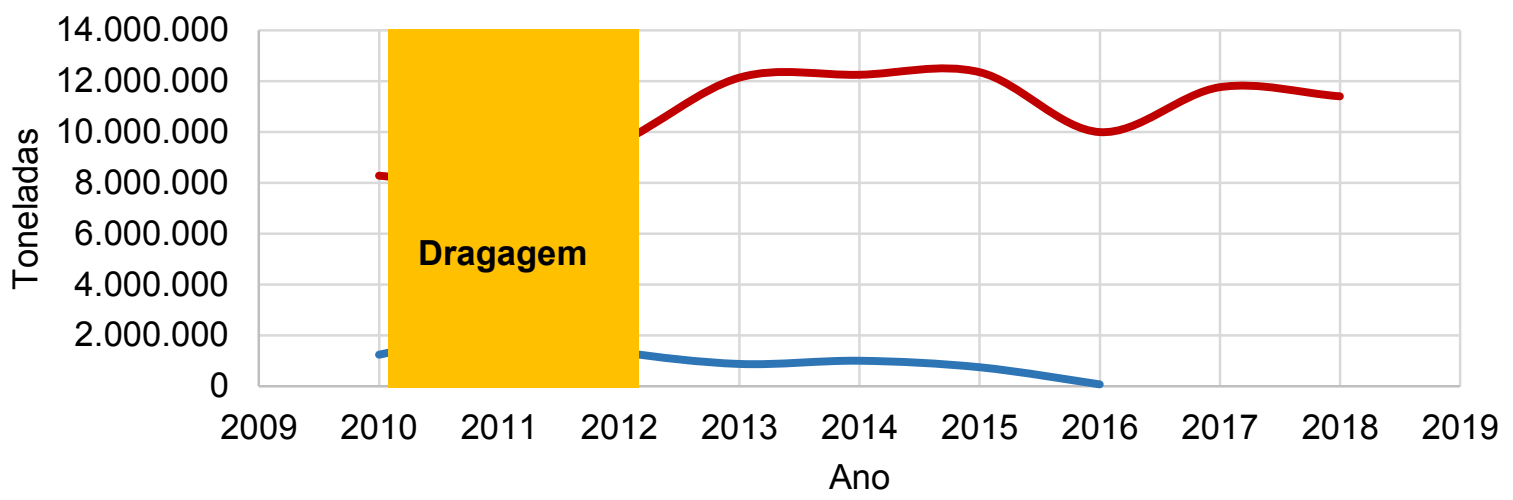

- Graneis e Carga Geral _Carga Conteinerizada

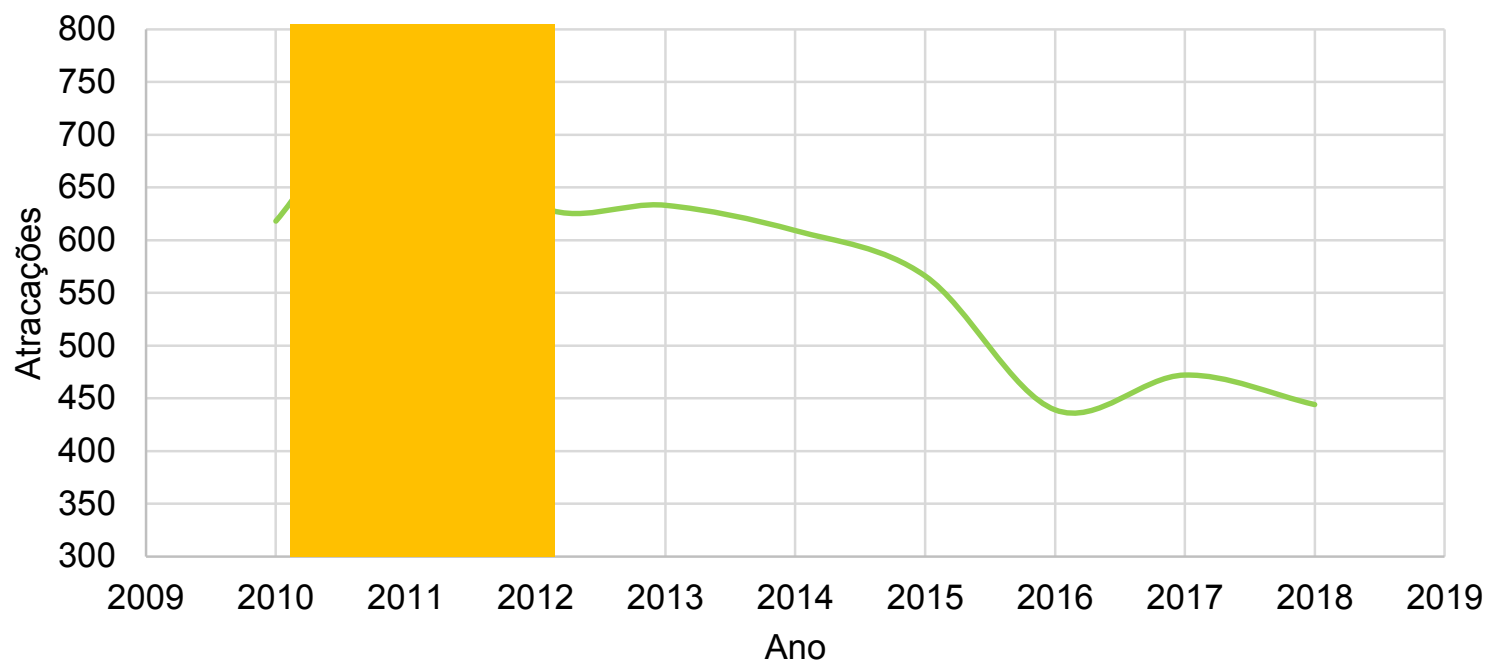

Figura 4-10: Toneladas movimentadas e número de atracações de 2010 a 2018 no Porto de São Francisco do Sul.

Fonte: Elaboração própria a partir de dados da ANTAQ, 2019.

O Porto de São Francisco do Sul apresentou melhoria na movimentação de cargas, com pequena queda em 2016 e recuperação do ano subsequente. Já o número de atracações exibiu variação mais significativa em termos percentuais, com forte queda, em relação ao ano de 2011, quando houve o maior número de atracações da série. Nesse mesmo ano, 2011, a movimentação portuária foi a menor, em toneladas.

\subsection{Observações adicionais}

Observa-se nos gráficos que há grande variação de resultados, apesar de todos portos apresentados terem sido contemplados por dragagens de aprofundamento. Para os atores tomadores de decisão quanto à alocação de recursos, esses parâmetros são pouco conclusivos e deficientes como indicadores de desempenho.

Parâmetros relacionados aos métodos gerenciais adotados pelas unidades portuárias devem ser pesquisados a fundo, e a partir deles, o uso de novos indicadores relacionados à capacidade dessas unidades de interface comercial de 
estabelecerem novos negócios. Para isso, não apenas o canal de acesso deve ser navegável pelas embarcações de interesse comercial no porto, mas a infraestrutura portuária e planejamento logístico devem suportar o fluxo de escoamento das cargas.

Tome-se como exemplo os Portos de Salvador e Aratu que se encontram geograficamente próximos, e são atendidos pela mesma malha logística, sendo que o Porto de Salvador se encontra na região metropolitana, o que constitui mais um desafio de logística. Além disso, o Porto de Aratu não movimenta carga conteinerizada. No entanto, os resultados do Porto de Salvador são melhores que o de Aratu em termos de crescimento percentual. No mesmo período de análise, o Porto de Salvador teve crescimento da ordem de $43 \%$, enquanto que o Porto de Aratu teve crescimento de $16 \%$ na movimentação de cargas.

Outro exemplo, o Porto de Itajaí, é um Porto com boa infraestrutura de serviços e está localizado em uma região que conta com bom apoio logístico, fruto de investimentos públicos, subsídios e capital privado advindo de expertise em serviços de transportes, alfandegamento, armazenamento e logística (SILVEIRA, 2018). Apesar disso, o Porto de Itajaí, apresentou queda expressiva, conforme ilustrado na Figura 4-8 em sua movimentação. Dessa forma, é preciso averiguar o plano de gerenciamento de negócios e contratos.

Em contrapartida, o Porto do Rio Grande, localizado em uma região estuarina, com alta taxa de assoreamento, durante a execução da dragagem iniciou expressivo aumento na movimentação de cargas.

Essas variações levam a questionamentos, outros, que a infraestrutura e disponibilidade de corredores de escoamento. É preciso que se investigue instrumentos de gestão e planejamento comerciais e parâmetros relacionados, que são essenciais para que resultados positivos sejam alcançados em corporações empresariais, e sua aplicação ao setor portuário.

Esses instrumentos podem indicar a resposta aos níveis de variação nos resultados obtidos pelos portos, em números de contratos de serviços, movimentação de carga, entre outros.

\section{CONCLUSÕES}

\subsection{Indicadores para critérios de priorização de dragagem}

Considerando-se a necessidade de critérios de "escolha" para alocação de recursos para dragagem, e os resultados obtidos na movimentação de cargas após execução de serviços de dragagem do PND I, em portos das regiões Nordeste, Sudeste e Sul, questionamentos são feitos acerca da capacidade gerencial do porto de transformar oportunidades de mercado em ganhos reais.

Além das movimentações de carga apresentadas no item 4, corrobora para esta sugestão, as atualizações dos Planos Mestres dos Portos, referentes ao $3^{\circ}$ Ciclo (2016/2019), disponíveis no site do Ministério da Infraestrutura, que trazem um capítulo que trata da gestão administrativa e financeira do porto em questão.

O Capítulo 8 dos Planos Mestres, sobre gestão administrativa e financeira da administração do porto, traz informações sobre o modelo de gestão adotado e os instrumentos de planejamento e gestão, dentre outras. Percebe-se em muitos dos portos, a ausência de um plano de negócios, plano comercial estruturado, além de dificuldades com sistemas de tecnologia.

Sendo assim, dois campos selecionados pelo estudo PPRISM, de 2012, para avaliação de desempenho portuário, e apresentados a seguir, demonstram 
VI CIDESPORT/2019

Congresso Internacional

de Desempenho Portuário

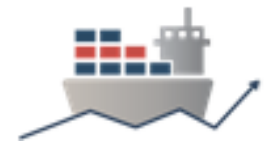

indicadores relacionados ao desempenho da gestão dos portos e podem ser úteis na avaliação da capacidade gerencial desses portos.

\subsubsection{Estrutura e tendências do mercado}

O conhecimento da estrutura de mercado e suas tendências (em uma determinada área ou região) auxilia nas tomadas de decisões gerenciais e, o consequente estabelecimento de estratégias e políticas de preços dos atores envolvidos em uma fatia específica do mercado (ALMEIDA E SILVA, 2015).

Para se entender a estrutura do mercado e definição da estratégia de negócios de uma empresa, é determinante entender o nível de concentração de um dado mercado. A partir do conhecimento da estrutura e tendências de mercado, uma corporação pode traçar sua estratégia de atuação focando a região geográfica, perfil de consumidor, meta de volume de negócios, etc. Um bom plano estratégico leva em consideração possíveis mudanças no mercado, desenvolvendo capacidade de adequação de metas por parte da corporação.

Sendo assim, é necessário que se crie um ambiente empresarial nos portos públicos, e para tanto, algumas mudanças podem ser feitas no cenário da administração pública, melhorando sua eficiência organizacional conforme as seguintes orientações (WORLD BANK, 2007):

- Adoção de práticas de planejamento corporativo, baseado na formulação de estratégias de um grupo de envolvidos, e não sob a responsabilidade de uma figura pessoa;

- Planejamento do desenvolvimento de Recursos Humanos, com desenvolvimento de carreiras. Organizações que falham por não implementar esse quesito tendem a apresentar funcionários pouco motivados e com alta taxa de rotatividade;

- Uso de sistemas de gerenciamento de informação; e

- Desenvolvimento de tecnologia de comunicação e Troca Eletrônica de Dados. Como empresas de serviços, os portos precisam garantir a manutenção de seus negócios por meio da manutenção de contratos de serviços e aquisição de novos negócios. Os gestores portuários devem medir e monitorar seus resultados, com o uso de indicadores que reflitam de forma real sua eficiência ou desempenho, e para tanto, há diversos métodos de gerenciamento disponíveis como o Balanced Scorecard, Six Sigma, Gestão da Qualidade Total, Gestão por Objetivos, Modelo de Excelência Empresarial, e outros (IBRAHIMI, 2009).

Ibrahim (2009) sugere o uso do Balanced ScoreCard também conhecido pela sigla BSC, como ferramenta de avaliação do desempenho da gestão de portos. O modelo BSC abrange as áreas estratégicas que indicam o desempenho da empresa. São elas, a área financeira, clientes, processos de gestão interna, e perspectiva aprendizado e crescimento da empresa.

\subsubsection{Governança}

A gestão portuária moderna deve considerar o contexto em que o porto está inserido, e para isso é necessário que as ações dos vários atores envolvidos estejam alinhadas e coordenadas para um objetivo comum, fazendo com que o porto, ou um cluster de portos seja o indutor da competitividade regional (VIEIRA et al, 2011).

Corroboram à gestão moderna, os modelos de governança. Um modelo de governança tem como função identificar objetivos estratégicos, apontar os riscos e 


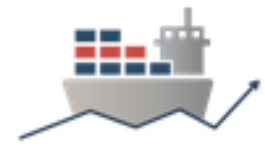

sua repartição entre os atores, e definir os princípios operacionais e o grau de transparência que se deseja dar às informações da corporação, que contribuem para a construção de um ambiente mais estável e seguro para a realização de investimentos (ROCHA et al. 2016).

Theocharis, 2016, apud Mokone, 2016, explica que governança são as ações do corpo de uma organização para garantir a adesão a um grupo de regras, regulamentos e orientações previamente estabelecidas. E ainda, que existe governança quando o poder de uma autoridade é exercido pela organização no gerenciamento de assuntos gerais.

No setor portuário, a governança significa, de forma direta, adotar um modelo de gestão cooperativo, em que as Autoridades Portuárias não exerçam controle soberano. A participação dos atores envolvidos é ativa na formulação dos objetivos da corporação, bem como os meios para alcançá-los (VIEIRA et al, 2011).

Sendo, assim, no campo da governança portuária, a Organização Europeia de Portos Marítimos propõe alguns indicadores:

- Integração do cluster com o objetivo de se avaliar o grau de iniciativas da autoridade portuária para a integração dos atores dos portos de um cluster;

- Informações sobre a responsabilidade corporativa e social indicando quais esforços são feitos para melhoria constante da responsabilidade; e

- Gerenciamento autônomo, que indica se a autoridade portuária trabalha com características que permitam o desenvolvimento de novas iniciativas.

Esses indicadores norteiam ações a serem desenvolvidas nos portos em nível de governança, mas é necessário que os gestores sejam escutados para que se reconheçam as dificuldades já presentes no sistema, e para que sugestões sejam acolhidas na criação de indicadores factíveis e que representem um objetivo comum.

\section{CONSIDERAÇÕES FINAIS}

Para contratar as dragagens necessárias aos portos públicos, e sabendo-se o quão onerosos são esses serviços, é necessário que critérios de seleção e priorização dos portos para alocação de recursos de dragagem sejam aplicados.

Uma avaliação não aprofundada dos resultados de movimentação de cargas pós obras de dragagem, com bases em dados da ANTAQ, mostrou que a dragagem não é o único fator determinante para melhoria nas movimentações. Há variações consideráveis dentre os diversos portos de três regiões geográficas diferentes, e a simples observação desses dados é inconclusiva.

Sendo assim, questiona-se quais fatores influenciam positivamente alguns portos, e outros não, sabendo-se que os Portos Públicos organizados são submetidos à administração exercida pela União, ou àquelas delegadas a municípios, estados ou consórcios públicos.

Fatores operacionais são comumente considerados para avaliação de desempenho dos portos na forma de indicadores. Porém, percebe-se a ausência de indicadores relacionados à gestão portuária brasileira, tanto em nível administrativo, como de governança, por parte das autoridades portuárias.

Vários estudos nesse sentido, o da avaliação da gestão, têm sido desenvolvidos, para a concepção e aplicação de indicadores de gestão, como por exemplo scorecards, Em portos brasileiros, recomenda-se que os gestores portuários sejam ouvidos, apontando os maiores entraves que o setor tem sofrido em termos gerenciais, e que acabam atravancando o crescimento. 
O desenvolvimento desses indicadores e aplicação periódica dos mesmos, com o propósito de nortear a priorização de investimentos em obras de dragagem, pode auxiliar, ainda, na criação de benchmarks de gestão no sistema portuário. Para isso a atuação da autoridade portuária é essencial no sentido de criar integração entre os atores de uma unidade portuária ou de um cluster, promover iniciativas de desenvolvimento e um ambiente coorporativo seguro para investimentos e com perspectivas de desenvolvimento socioeconômico.

Finalmente, implementar indicadores de gestão, é implementar no sistema portuário uma forma de se buscar maior nível de organização dessas empresas, e maior equilíbrio de condições de competitividade.

\section{REFERÊNCIAS}

BRASIL. Ministério da Infraestrutura. Programa Nacional de Dragagem. Publicado em fevereiro de 2015.2 Disponível em:<https://www.infraestrutura.gov.br/consultas_publicas/89-portos-menulateral/5471-programa-nacional-de-dragagem-pnd.html>. Acesso em: 06/08/2019.

CARVALHO A. X. Y; COUTINHO P. C.; OLIVEIRA A. R.; P A. P. BRITTO; LUSTOSA, P. R. B. Caracterização do fluxo de cargas e indicadores de concorrência entre os portos brasileiros. Instituto de Pesquisa Econômica Aplicada. 2015

DUTRA, A.; RIPOLL-FELIU, V. M.; ENSSLIN, S. R.; ENSSLIN, L.; CASTELLÓ, E. T. T. Indicadores de Avaliação do Desempenho Portuário: Uma Análise a Partir da Literatura Científica EnANPAD, XXXVIII Encontro da ANPAD. Rio de Janeiro, 2014.

ESPO, European Sea Ports Organization. Port Performance I Port Performance Indicators. Selection and Measurement indicators.Port PeRformance Indicators: Selection and Measurement PPRISM. Project Executive report, 2012.

HARALAMBIDES, H E. Gigantism in container shipping, ports and global logistics: a time- lapse into the future. Vol. 5, No. 1. Maritime Economics Logistic (2019) 21:1-60.

IBRAHIMI, K. Performance Indicators and Port Authority Management. ASECU -5 th International Conference "Market Functionality and Institutional Reforms", Tirana, 2009

LIMA, M. M. T. Gestão Portuária com Subsídios de Modelagem Computacional para Projetos de Dragagem. Tese de Doutorado apresentada ao Programa de PósGraduação em Engenharia Civil, UFRJ/COPPE, Rio de Janeiro, 223 p. 2012.

LOPES, C. R. B. A importância da dragagem no cenário econômico nacional. Monografia apresentada ao Centro de Instrução Almirante Graça Aranha como requisito parcial para aprovação no Curso de Aperfeiçoamento para Oficiais de Náutica (APNT) e obtenção do título de Capitão de Cabotagem. Rio De Janeiro, 2014.

MENEGAZZO, L.; PETTERINI, F. Maiores Navios no Mundo, mais um Desafio no Brasil: uma análise do Programa Nacional de Dragagem. Estudos Econômicos, São Paulo, vol.48 n.1, p. 175-209, jan.-mar. 2018. 
VI CIDESPORT/2019

Congresso Internacional

de Desempenho Portuário

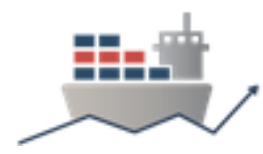

MOKONETHE, T.; Impact of Governance Structure Onport Performance: A Case of Durban Port South Africa. Dissertação submetida para obtenção de título de mestre pela World Maritime University. Maritime Affairs. Shipping Management and Logistics, 2016.

ROCHA, C. R.; BRITTO, P. A. P.; UDERMAN, S. Abertura de capital e Governança Corporativa no setor portuário brasileiro. Revista de Governança Coorporativa, São Paulo, v. 3, n.1, art.1, pp. 1-23, set. 2016.

SILVEIRA, M. R. Transportes e a logística frente à reestruturação econômica no Brasil. Mercator, Fortaleza, v. 17, e17008, 2018.

SCHWAB, K.; SALA-I-MARTIN, X. The Global Competitiveness Report 2014- 2015, Full Data Edition, World Economic Forum, Genebra, 2014.

UN, United Nations. Port Management SeriesPort Performance Linking Performance Indicators to Strategic Objectives. Volume 4. New York e Geneva, 2016.

VARUM, C.; VALENTE, H.; RESENDE, J.; PINHO, M.; SARMENTO, P.; JORGE, S. Economia Industrial - Teoria e Exercícios Práticos. Edições Sílabo, Lda.1ª Edição Lisboa, 2016.

VIEIRA G. B. B.; MILAN, G. S.; KLIEMANN NETO, F. J.; RODRIGUES, S. L. A.; RAMOS, F. F. N. Ações de governança em clusters portuários: a proposição de um modelo conceitual no contexto do porto de Buenos Aires. XXXI Encontro Nacional de Engenharia de Produção. Inovação Tecnológica e Propriedade Intelectual: Desafios da Engenharia de Produção na Consolidação do Brasil no Cenário Econômico Mundial. Belo Horizonte, MG, Brasil, 04a 07de outubro de 2011.

WINTER, J.; Aplicação do instituto da demurrage de conteinêres na importação no direito brasileiro. Dissertação apresentada para obtenção do título de mestre pela Fundação Getúlio Vargas, FGV Direito SP, São Paulo, 2017.

WORLD BANK. Alternative Port Management Structures and Ownership Models. 2007. 